\title{
The measurement of muscle strength in patients with peripheral neuromuscular disorders
}

\author{
CM WILES, Y KARNI \\ From the Departments of Clinical Neurophysiology and Physiotherapy, The National Hospital for Nervous \\ Diseases, Queen Square, London, UK
}

SUMMARY The variability of voluntary isometric strength measurements has been assessed in normal subjects and patients with peripheral neuromuscular disorders. Knee extensor strength was measured in a muscle testing chair 13 times over 5 months in each of six normal subjects: coefficients of variation (CV) ranged from 4.5 to $14.0 \%$ (mean $8.5 \%$ ) for individual legs in different subjects. Paired measurements of the strength of several clinically weak muscle groups were made 1-4 days apart in 20 patients using both a handheld dynamometer and the muscle chair technique: the test/retest correlation was high $(r=0.97, p<0.001)$. Visual biofeedback did not affect the strength recorded in most cases. Each of five patients had the strength of six or seven clinically weak muscle groups measured by five examiners within a 24 hour period: the $\mathrm{CV}$ for the five examiners ranged from $3 \cdot 6-27 \cdot 3 \%$ (mean $12 \cdot 8 \%$ ). A single examiner measuring the same groups on five occasions in three patients obtained a mean CV of $8.9 \%$. Sources of variation are analysed and it is concluded that, with certain precautions, voluntary strength measurements offer a simple, reliable and acceptable method for monitoring change in patients.

Measurement of the strength of a maximum voluntary contraction (MVC) is, the simplest and most direct means of assessing the amount of active muscle in a particular group. ${ }^{1}$ In disease MVC is reduced either because there is a reduced amount of contractile material or because the processes leading to its activation are impaired or both. Changes in MVC therefore may allow the progress of the underlying disorder to be monitored and clinicians have traditionally used manual strength testing for this purpose. A variety of semiquantitative techniques for scoring muscle strength have been used, ${ }^{2-4}$ but these are subjective, non-linear and only score clinically detectable weakness. Spring balances, cable tensiometers and different types of strain gauge dynamometer have been used for many years to obtain absolute values for strength..$^{5}$ In neurological practice strength measurements have been used to assess weakness in poliomyelitis, ${ }^{6-8}$ Guillain-Barré syndrome, ${ }^{9}$ muscular dystrophy, ${ }^{10-14}$ inflammatory myopathy, ${ }^{15-17}$ thyroid muscle disease, ${ }^{18}$ osteomalacic myopathy, ${ }^{19}$ acute infectious disease ${ }^{20}$ and

Address for reprint requests: Dr CM Wiles, The National Hospital for Nervous Diseases, Queen Square, London WC1N 3BG, UK.

Received 4 March 1983 and in revised form 4 May 1983. Accepted 14 May 1983 other disorders. In this paper we analyse some of the sources of variability in voluntary strength measurements in patients with peripheral neuromuscular disorders and normal subjects with a view to encouraging the more rigorous use of this potentially powerful but simple technique as a routine.

\section{Methods}

(1) Variation of knee extensor strength in normal subjects The MVC of the right and left knee extensors was measured 13 times over a period of 5 months in each of six healthy subjects (three male, three female, aged 21-51 years). No subject undertook regular athletic training. Each subject was tested in the early morning, lunchtime or early evening on different occasions.

Maximum voluntary isometric strength was measured with the subject strapped sitting in a special muscle testing chair ${ }^{21}$ with a back support and the hip and knee flexed to a right angle; $; 2$ an inextensible strap looped around the ankle (above the malleoli) and passed to a strain gauge (Strainstall $1886 \mathrm{D})$. The bridge output from the strain gauge was amplified and the force trace displayed on the oscilloscope of a Medelec MS- 6 and also recorded on light sensitive paper. The strain gauge was calibrated against known weights and gave a linear response over the range of forces recorded.

After explanation to the subjects (only one of whom had 
performed such tests previously) and one or two test contractions three definitive contractions each lasting about $5 \mathrm{~s}$ were made over a 1 minute period. Subjects were told not to "kick" but to build up force steadily and rapidly and they were verbally exhorted and encouraged; that is, they routinely obtained auditory biofeedback. ${ }^{23}$ MVC was taken as the highest peak force maintained over one second in each leg. To test the effect of visual biofeedback on a separate occasion a second oscilloscope beam was used such that after the first contraction a target was set at, or $20 \%$ above, the force of that contraction. The subject was told that the target was approximately at the level of his initial contraction and he was asked to try and raise his MVC to a higher level.

\section{(2) Day to day variation in MVC in patients}

A number of patients with peripheral neuromuscular disorders were referred for strength measurements as part of their clinical assessment. Twenty patients (four with neurogenic weakness and 16 with myopathic disorders, eight male, 12 female, aged 15 to 81 years) had strength measurements performed on two occasions by a single observer not more than four and not less than one day apart. The only criterion used in selecting patients was that the underlying condition should not be rapidly changing as judged clinically. Measurements were made either at the bedside (ward or intensive care unit) or in the EMG laboratory.

When practicable knee extensor MVC and the effect of visual biofeedback was measured as described for normal subjects. In 12 patients several other clinically weak muscle groups were measured using a handheld electronic myometer (Penny \& Giles Transducers Ltd, Dorset, England). The principle of the technique is that the myometer, which contains a small displacement transducer, is interposed between the examiner and a standard point on the patient; the examiner then encourages the patient to maximally resist a counter force. When the examiner overcomes the patient's resisted movement the peak force recorded is that required to "break" the patient's contraction and hence is virtually isometric. ${ }^{12} 142425$ Clearly the positioning of the limb part and the relative position of the myometer on the body (that is, the length of the moment arm) must be carefully standardised for serial measurements in a given patient (see table 1). If the examiner is not able to overcome the patient's contraction and the moment arm cannot be extended then the maximum force cannot be recorded. The myometer records up to 300 Newtons (N) which is well below MVC for many muscle groups in healthy adults. Attempts to record higher forces using this technique are clumsy or impossible for the average examiner and hence the technique is not appropriate for establishing the normal ranges of several larger muscle groups in adults.

Although limb positions were standardised in a manner similar to that described by Scott et al $^{14}$ no rigidly fixed pattern was applied. Muscle groups were selected and positioned according to whether they were clinically appropriate, for ease and comfort of measurement both for patient and examiner, and to facilitate standardisation and repeatability. For very weak muscle groups positions were preferred where gravity was eliminated and where the limb part could be viewed directly by the patient especially if there was sensory loss. For each muscle group the routine was explained carefully to the patient, he/she was instructed to look at the limb part under test where possible and then three or four measurements were made and, for this study, the MVC was expressed as the mean of the best three (vide infra).

Table 1

\begin{tabular}{|c|c|c|}
\hline Muscle group & Subject position & Myometer position \\
\hline Shoulder abductors & $\begin{array}{l}\text { Subject sitting; shoulder abducted to } 90^{\circ} \text { : Elbow flexed } 90^{\circ} \text { : } \\
\text { forearm pronated-also done with subject supine }\end{array}$ & $\begin{array}{l}\text { Just proximal to lateral } \\
\text { epicondyle of humerus }\end{array}$ \\
\hline Elbow flexors & $\begin{array}{l}\text { Subject supine: shoulder abducted } \sim 30^{\circ} \text { from trunk, upper arm } \\
\text { supported: Elbow flexed to } 90^{\circ}: \text { forearm/palm supinated }\end{array}$ & $\begin{array}{l}\text { Just proximal to wrist } \\
\text { crease (flexor surface) }\end{array}$ \\
\hline Elbow extensors & $\begin{array}{l}\text { As above: upper arm stabilised by examiner: may also be done } \\
\text { with subject in position as for shoulder abductors (sitting), } \\
\text { forearm supinated }\end{array}$ & $\begin{array}{l}\text { Just proximal to wrist } \\
\text { crease (extensor surface) }\end{array}$ \\
\hline Wrist extensors & $\begin{array}{l}\text { Subject supine or sitting: forearm supported and pronated: wrist } \\
\text { extended: fingers flexed }\end{array}$ & $\begin{array}{l}\text { Just proximal to } 2 \mathrm{nd} / 3 \mathrm{rd} \\
\text { metacarpal heads }\end{array}$ \\
\hline Hip flexors & $\begin{array}{l}\text { Subject supine: hip and knee flexed to } 90^{\circ} \text { : ankle supported } \\
\text { by examiner }\end{array}$ & Just proximal to patella \\
\hline Hip abductors & $\begin{array}{l}\text { Subject lying on side: hip and knee extended: lifting against } \\
\text { gravity or: supine: knee extended: ankle supported by examiner } \\
\text { so that hip flexed } 10-20^{\circ}\end{array}$ & Lateral condyle of femur \\
\hline Knee flexors & $\begin{array}{l}\text { Subject seated on high chair/couch: hip and knee flexed to } 90^{\circ} \text {. } \\
\text { Knee held by examiner to prevent hip flexion }\end{array}$ & $\begin{array}{l}\text { Just proximal to malleoli of } \\
\text { ankle posterior suface } \\
\text { of leg }\end{array}$ \\
\hline Knee extensors & As for knee flexors & $\begin{array}{l}\text { As for knee flexors } \\
\text { - anterior aspect of leg }\end{array}$ \\
\hline Neck flexion & Patient supine: neck flexed to $40-60^{\circ}$ & Forehead-centrally \\
\hline
\end{tabular}


(3) Variation of strength in patients between examiners In five patients (three with peripheral neurogenic weakness, two with polymyositis, aged $31-53$ years, three male, two female) five observers (four physiotherapists, one doctor) each made measurements of seven clinically weak muscle groups (table 1, excluding neck and knee flexors) using the hand held myometer. Only one of the examiners (author YK) was especially experienced in the use of the technique whilst the others had had instruction and limited practice over two days. All measurements in a particular patient were made within 5 hours except in one where two examiners made sets the following day. Examiners were not aware of the results obtained by their colleagues. One examiner (YK) went on subsequently to make five sets of measurements in the same muscle groups on one day in three further patients (one male aged 57, two females aged 53,82 years). YK had no knowledge of any of the values obtained until the entire series of measurements was complete as the myometer was read by an independent observer.

\section{Results}

(1) Knee extensor strength in normal subjects (figs 1 and 2)

For each subject MVC for each knee extensor fell within the range for the strongest leg predicted for body weight. ${ }^{21}$ Each subject was right-handed and in three (subjects $2,3,6$ ) the right leg was systematically stronger than the left (paired $t$ test, $\mathrm{p}<0.05$ ) whilst in subject 4 who had had a right medial menisectomy 20 years previously the left leg was stronger $(p<0 \cdot 001)$. There was neither a systematic

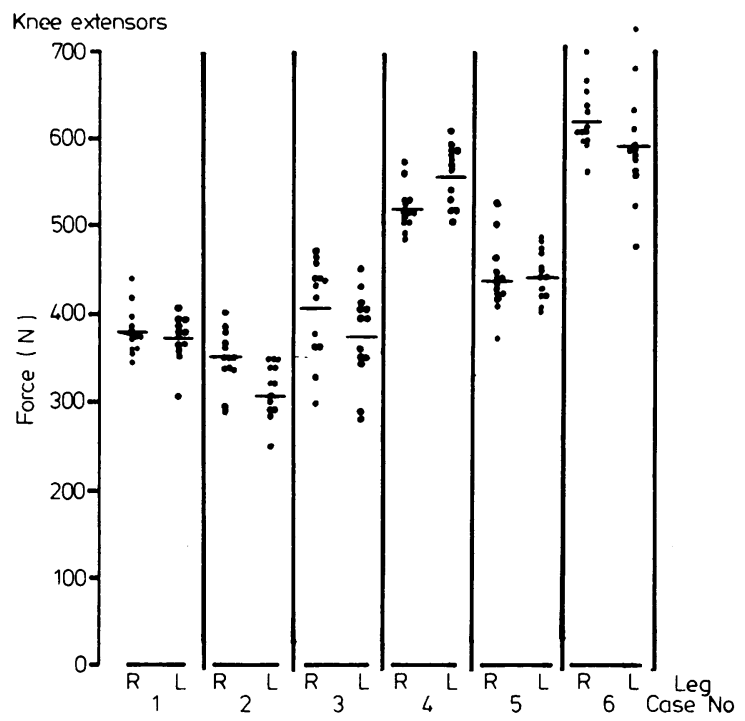

Fig 1 Force of maximum voluntary isometric knee extensor contractions in both legs of six subjects on 13 occasions. Bar represents mean value.

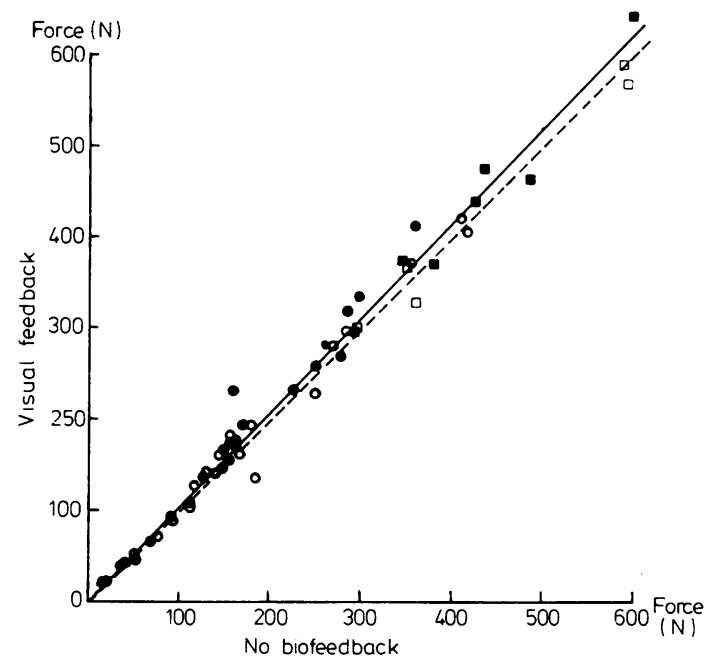

Fig 2 Force of maximum voluntary isometric knee extensor contractions in both legs of six normal subjects (ㅁ) and 21 patients with neuromuscular disease $(0)$ without ( $x$ axis) and with (y axis) visual biofeedback. Filled symbols -right leg, open-left leg. Continuous line is least square regression $y=0.50+1.04 x, r=0.99, p=$ $<0.001, n=54$ legs. Broken line = line of indentity.

change in muscle strength with time of day (from 0800-2000 hours) nor over the 5 month period in any subject. Coefficients of variation (standard deviation/mean $\times 100 \%$ ) for the 13 measurements ranged from $4.5-14.0 \%$ (mean $8.5 \%$ ) and tended to be similar for the two legs in a given subject. Visual biofeedback significantly enhanced the force recorded in only one limb of one subject (fig 2)

\section{(2) Day to day variation in $M V C$ in patients}

A total of 95 pairs of strength measurements were made 1 to 4 days apart in 20 patients. The muscle chair technique for knee extensors was used for 39 pairs (right and left legs) and the hand held myometer utilised in 56 pairs including neck flexion (eight pairs), shoulder abduction (seven pairs), elbow flexion (10 pairs), hip abduction (11 pairs), hip flexion (12 pairs) and occasionally wrist extension, elbow extension, finger extension, abductor digiti minimi and hip extension. The test/retest values correlated closely (fig 3, r $=0.97, \mathrm{p}<0.001$ ) but clearly there were cases where the differences were substantial. In fig 4 the incidence of the various percentage differences between test and retest values (difference between pairs of values $\times 100 \%$ / mean of paired values) is shown. In $80 \%$ of cases the error was $<20 \%$ (median $10.5 \%$ ). There was no less variation in the krree extensor measurements in the muscle chair than in other groups using the myome- 


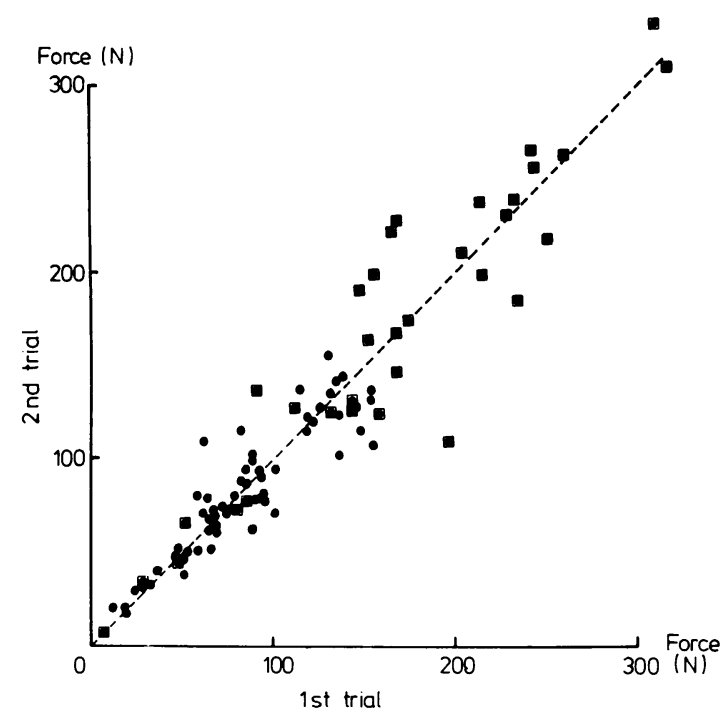

Fig 3 Force of maximum voluntary contractions in 95 muscle groups ( $\mathrm{Z}$ = knee extensors using muscle chair, - $O$ other groups - see text, closed symbols - right-open symbols-left) in 20 patients on 2 days, measured by one examiner. Regression line (least squares), $y=0.27+$ $0.99 x, r=0.97, p=<0.001$. ( $x=$ force on first occasion, $y=$ force on second occasion).

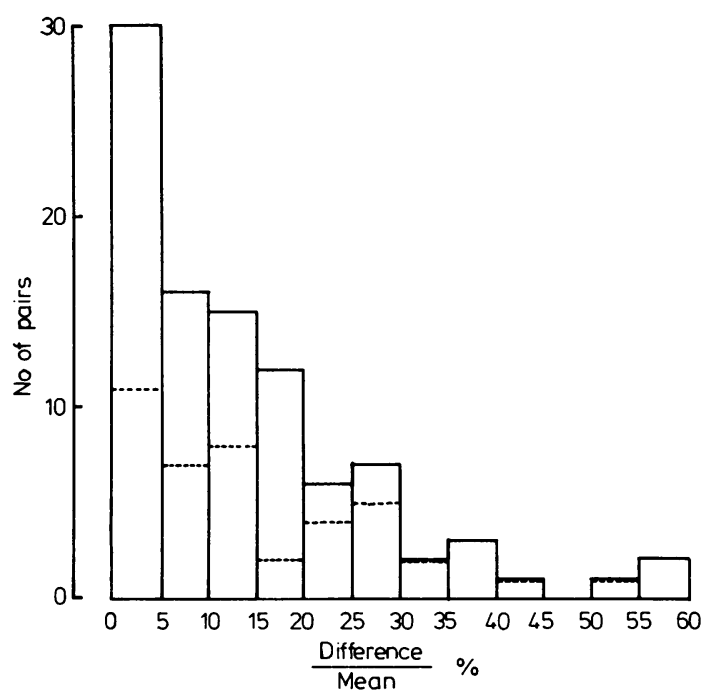

Fig 4 Histogram of the frequency of differing sizes of percentage difference between pairs of MVC measurements on two separate days (difference between pair of values $\times$ $100 \% / m e a n$ of pair): 95 pairs of measurements (39 knee extensors below dotted lines, 56 pairs in other groups above dotted lines) in 20 patients, same data as fig 3. ter (fig 3). When 12 patients who had each had more than five groups assessed were considered sparately the percentage differences for test/retest showed considerable variation both within patients (for example, 0 to $24.3 \%$ for different muscle groups) and between patients (median value for all muscle groups $3 \cdot 2-19 \cdot 0 \%$ ). There was no significant difference in variability between right and left knee extensors and only infrequently in patients did visual biofeedback appear to result in higher MVC (fig 2).

\section{(3) Variation in strength in patients-different observers.}

Seven muscle groups (table 1, less neck and knee flexors) were tested in four patients and all but knee extension in the fifth using the myometer. Three values for each muscle group in each patient were obtained in rapid succession by each of the five examiners. These data were analysed to see how closely the best two MVCs out of each group of three values corresponded. In a patient making a full effort the percentage difference between the best two values can be expected to be small. ${ }^{26}$ The median percentage difference was $4.6 \%$ with $81 \%$ of the differences being less than $10 \%$ (fig 5A). There was no clear difference between patients or muscle groups in this respect, but one of the examiners consistently obtained slightly more variable results than the other four $(65 \%$ errors $<10 \%$ compared to $91,82,79,88 \%$ respectively).

The percentage differences for the best two contractions were calculated separately for the 19 muscle groups in three patients measured on five occasions by YK (fig 5B). The median value was $5.4 \%$ (range $0-54.8 \%, 74 \%$ values $<10 \%$ ); the distribution of differences was not significantly different from that found with five examiners (compare fig $5 \mathrm{~A}$ and $5 \mathrm{~B})$.

No particular measurement of a group of three was regularly higher or lower than the other two. When the results for each muscle group obtained by each examiner were compared using either the highest measurement or the mean of three the variability between observers was least using the mean values and these are used for the following analyses. Rank analysis of mean measurements for each muscle group obtained by each examiner disclosed that no examiner consistently produced higher or lower results than the others. Analysis by order of testing (and hence time of day) showed no tendency for those measuring later to obtain lower values, that is, no fatigue effect.

One way analysis of variance of the three values obtained by each of the five examiners for each muscle group showed that in $25 / 34$ groups the mean values between observers differed significantly $(p<$ 


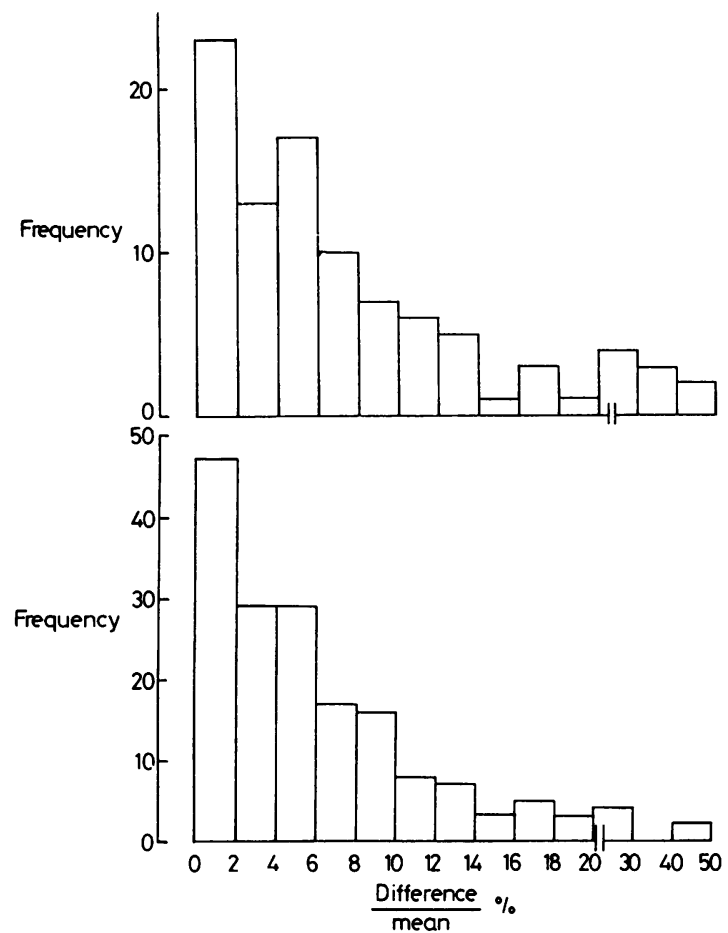

Fig 5 A. Histogram of the frequency of differing sizes of percentage difference between the best two of three measurements of MVC obtained by 5 examiners in a total of 34 muscle groups in 5 patients (total pairs of measurements $=170$ ). B. Histogram of the frequency of differing sizes of percentage difference between the best two of three measurements of MVC obtained by 1 examiner measuring 6 or 7 muscle groups on five occasions in 3 patients (total pairs of measurements $=95$ ).
0.05) whilst significant differences between the five means emerged in only $7 / 19$ muscle groups tested by a single observer (YK). Coefficients of variation (CV) for the mean values for each muscle group are shown in table 2 . The mean $\mathrm{CV}$ for all muscle groups measured by the five examiners was $12.8 \%$ and for a single examiner making five sets of measurements on each muscle group was $8.9 \%$. Two way analysis of variance of the coefficients in table $2 \mathrm{~A}$ indicated no significant differences between patients but some differences between muscle groups $(p<0.02)$. If the wrist extensor data was eliminated there were no significant differences between the other six muscle groups tested. No correlation was found between $\mathrm{CV}$ for different muscle groups and absolute force of contraction.

\section{Discussion}

Our previous experience of measuring muscle strength in patients has been that it is a simple, useful and acceptable way of delineating changes in one important aspect of motor function on a linear scale. Many patients with muscle weakness readily appreciate the benefit in accuracy of attributing an absolute value to strength rather than relying on the doctor's recollection of it over weeks or months. It is self evident, as several patients have commented to us, that the absence of measurements from one clinic visit to the next increasingly biases the doctor towards the patients' own view of their progress, a view which, although frequently correct, is influenced by many factors ${ }^{27}$ other than change in strength. For most muscle and some peripheral nerve disorders it is change in strength which is the ultimate manifestation of improvement or deterioration in the underlying disease.

Table 2 Coefficients of variation for 5 sets of measurements either by 5 different observers (A) or on 5 occasions by one observer (B)

\begin{tabular}{|c|c|c|c|c|c|c|c|c|c|c|}
\hline & & \multicolumn{7}{|c|}{ Muscle groups } & & \\
\hline & & Sh. abd & Elb. $f x$. & Elb. ext. & Wrist ext. & Hip $f x$ & Hip abd. & Knee ext. & & \\
\hline $\mathbf{A}$ & $\begin{array}{l}\text { Patients } \\
\text { CP } \\
\text { EF } \\
\text { FF } \\
\text { TH } \\
\text { SS } \\
\text { mean } \\
\text { SD }\end{array}$ & $\begin{array}{r}15.9 \\
4.7 \\
17.7 \\
10.0 \\
10.8 \\
11.8 \\
5.1\end{array}$ & $\begin{array}{r}5.1 \\
16.0 \\
10.0 \\
1.7 \\
8.9 \\
8.3 \\
5.4\end{array}$ & $\begin{array}{r}15.9 \\
9.4 \\
12.3 \\
11.2 \\
4.7 \\
10.7 \\
4.1\end{array}$ & $\begin{array}{r}15.9 \\
26.0 \\
27.3 \\
14.4 \\
16.9 \\
20.4 \\
5.8\end{array}$ & $\begin{array}{r}20.4 \\
9.5 \\
14.5 \\
11.5 \\
13.7 \\
13.9 \\
4.1\end{array}$ & $\begin{array}{r}11.0 \\
9.7 \\
20.6 \\
13.9 \\
10.8 \\
13.2 \\
4.4\end{array}$ & $\begin{array}{l}\text { NT } \\
11.9 \\
12.1 \\
6.3 \\
14.7 \\
11.3 \\
3.6\end{array}$ & $\begin{array}{l}\text { mean } \\
14 \cdot 0 \\
12.5 \\
16.4 \\
9.9 \\
11 \cdot 5 \\
12.8 \\
-\end{array}$ & $\begin{array}{c}\text { s.d. } \\
5 \cdot 3 \\
6 \cdot 9 \\
6 \cdot 0 \\
4 \cdot 5 \\
4 \cdot 0 \\
-\end{array}$ \\
\hline B & $\begin{array}{l}\text { CP } \\
M H \\
1 \mathrm{~W} \\
\text { mean }\end{array}$ & $\begin{array}{l}6 \cdot 0 \\
9 \cdot 0 \\
4 \cdot 2 \\
6 \cdot 4\end{array}$ & $\begin{array}{l}5 \cdot 7 \\
4 \cdot 4 \\
8 \cdot 9 \\
6 \cdot 3\end{array}$ & $\begin{array}{r}9.5 \\
13.0 \\
7.9 \\
10.1\end{array}$ & $\begin{array}{r}4.4 \\
11.6 \\
4.5 \\
6.8\end{array}$ & $\begin{array}{l}6 \cdot 8 \\
5 \cdot 7 \\
6 \cdot 5 \\
6 \cdot 3\end{array}$ & $\begin{array}{l}7.4 \\
\text { NT } \\
22 \cdot 0 \\
14.7\end{array}$ & $\begin{array}{l}\text { NT } \\
23 \cdot 5 \\
12.4 \\
17 \cdot 9\end{array}$ & $\begin{array}{r}6.6 \\
11.2 \\
9.0 \\
8.9\end{array}$ & $\begin{array}{r}1.7 \\
6.9 \\
6.6 \\
-\end{array}$ \\
\hline
\end{tabular}

NT $=$ not tested because of excessive weakness - MRC grade 1 . 
In normal subjects MVC fluctuated over a period of months but it is not possible to determine from the present data how much of this was due to fluctuations in excitation and how much to actual changes in muscle bulk. The non-systematic way in which the changes occurred suggest that differences in excitation processes especially "central drive" account for most of the variation but femoral nerve stimulation techniques would be required to elucidate this further. These results indicate the importance of demonstrating a trend over several sets of measurements in order to be certain of detecting true changes in strength. Occasionally a systematic change in strength is due to a learning effect. ${ }^{28}$ This tends to occur when a complex action involving several joints is tested. We have not observed such effects in normal subjects or patients provided that simple movements across a single joint are tested. Time of day of testing made little difference in our normal subjects.

If the voluntary strength recorded is truly maximal then the percentage differences between the best two contractions should be less than in submaximal efforts made without a target. In the stronger knee extensor of 50 normal subjects and 50 patients a median percentage difference of $2.1 \%$ (range 0 $7.7 \%$ ) and $2.3 \%$ (range $0-18.5 \%$ ) has been found. ${ }^{26}$ In this study (fig 5) we find a median percentage difference of just under $5 \%$ (range $0-54 \%$ ) in 265 sets of measurements on eight patients (fig 5A and B). We attribute this higher variability to the testing of six or seven different muscle groups repeatedly on the same day in each patient by one or several examiners. It is noteworthy that the results of a given set of measurements were no better when done repeatedly by one examiner than when done by five (compare fig 5A and $\mathrm{B}$ ) suggesting that the patients tried equally hard in both situations. A practical approach to the relatively few sets of measurements with high variability is to repeat the readings after a rest and to take MVC as being the mean of the best two which are within $10 \%$ of each other. If this cannot be achieved it may well be that a significant volitional factor is interfering with the assessment although this is usually obvious from the feel of the given contraction to the examiner and from the irregular nature of the force tracing if available.

Various feedback techniques have been used to encourage greater force production in this type of test. In 16 physiotherapy students combined auditory and visual feedback resulted in approximately a $10 \%$ increase in knee extensor strength over the "no feedback" condition whilst either technique alone had a smaller effect..$^{23}$ We routinely used auditory feedback and found that neither simple visual feed- back nor the setting of an artificially high target force made any systematic difference to most patients at least for the knee extensors. The occasional patient was apparently aided but some seemed distracted and did, if anything, less well. This form of visual feedback, using a force target, is to be distinguished from active visualisation of the limb part under test particularly if there is proprioceptive loss which is commonly recognised to be of importance in the assessment of strength in many neurological patients. Short-term (same day) variability assessed by one examiner is low (overall mean CV $8.4 \%$ ) but unpredictably poor results, for example, mean values with a CV of $20-25 \%$ were found in one muscle group each in two of the three patients and a similar effect is seen between several examiners (table 2). This element of unpredictability suggests that before conclusions are drawn about the significance of a change in strength the variability of the measurements for each of the muscles under test should be assessed. It is therefore desirable that several sets of measurements should be made by a single examiner before any therapeutic intervention is made: the alternative strategy is to have sufficiently frequent measurements such that over a period of time the variability of each muscle group under test can be assessed. The above techniques cannot be recommended for making "one off" measurements before and after a trial of therapy.

Repeatability of measurements over days or months has been infrequently studied in patients. In children with dystrophy high correlation coefficients for test/retest data are reported" ${ }^{11}$ but as can be seen from our own data (compare fig 3 and fig 4) this obscures the fact that some (unpredictable) patients may show quite wide variations in some (again unpredictable) muscles. Hosking $\mathrm{et} \mathrm{al}^{12}$ using a hand held myometer found that most measurements made within a month of the original set in 18 boys with Duchenne dystrophy were within $15 \%$ of the original whilst our study of pairs of measurements up to 4 days apart showed that the percentage difference was $<20 \%$ in $80 \%$ (median $10.5 \%$ ). It was of particular interest that the day to day variability of the knee extensors (39 pairs of measurements) measured using a superficially more rigorous technique in the muscle chair was no less than that of measurements made with the hand held myometer. We have not however compared measurements of knee extensor strength using both techniques.

In muscle disease the MVC of a muscle group reflects the amount of functioning contractile material assuming normal excitation processes. Our results are representative mainly of this group of patients. When weakness results from disorders of the central nervous system or the peripheral nerve 
changes in strength measurements principally reflect altered excitation processes and secondary changes in muscle mass. It is possible that the variability of measurements used for assessing motor function in, for example, a case of multiple sclerosis ${ }^{29}$ or stroke will be different from cases of inflammatory or dystrophic muscle disease where the nervous system is probably intact. Such uncertainties can be overcome by always ensuring adequate numbers of measurements such that variability is established as a routine in all muscle groups tested.

In conclusion we find that several muscle groups in patients with peripheral neuromuscular disorders can be satisfactorily and reproducibly measured using the hand held myometer and the muscle chair and suggest that the technique is highly appropriate for routine clinical application. We think that such measurements are most likely to be of clinical value if the following precautions are regularly taken:

(1) Comprehensive explanation to the patient; visualisation of the part of the body being tested; routine auditory feedback.

(2) The same examiner for each patient on successive occasions.

(3) Review of sets of measurements where the best two values vary by more than $10 \%$; if variation is non systematic pain or a volitional factor may be interfering; if strength systematically declines abnormal fatiguability is more likely; examination of the force records may elucidate.

(4) Frequent sets of measurements of more than one muscle group increase the likelihood of reliably detecting true changes in strength sooner.

We thank Dr R Willison for helpful advice and criticism, the physicians at the National Hospitals for Nervous Diseases and St Mary's Hospital, London, who referred patients for assessment, and the physiotherapists at the National Hospital for their assistance. This work was in part supported by a grant from the National Fund for Research into Crippling Diseases.

\section{References}

${ }^{1}$ Edwards RHT. Physiological analysis of skeletal muscle weakness and fatigue. Clin Sc 1978;54:463-70.

${ }^{2}$ Medical Research Council. Aids to the Examination of the Peripheral Nervous System. Memorandum No. 45. London: HMSO, 1976.

${ }^{3}$ Ziter FA, Allsop KG, Tyler FH. Assessment of muscle strength in Duchenne muscular dystrophy. Neurology (Minneap) 1977;27:981-4.

${ }^{4}$ Sandstedt PER, Henriksson KJ, Larsson LE. Quantitative electromyography in polymyositis and dermatomyositis. Acta Neurol Scand 1982;65:110-21.
${ }^{5}$ Regnier C. Description et usage du dynamometre. $J$ Ecole Polytechiques 1798;2:160-72.

${ }^{6}$ Lovett RW, Martin EG. Certain aspects of infantile paralysis with description of the method of muscle testing. JAMA 1916;66:729-33.

${ }^{7}$ Russell RW, Fischer-Williams M. Recovery of muscular strength after poliomyelitis. Lancet 1954 ;i:330-3.

${ }^{8}$ Russell RW. Poliomyelitis 2nd Edn. London: Edward Arnold, 1956:108-23.

${ }^{9}$ Osterman PO, Fagius J, Säfwenberg J, Danersund A, Wallin BG, Nordesjö LO. Treatment of the Guillain Barré syndrome by plasmapheresis. Arch Neurol 1982;39:148-54.

${ }^{10}$ Barwick DD, Newell DJ, Walton JN. Methandrostendase and mandrolase decanoate in muscular dystrophy. Neurology (Minneap) 1963;13:12-23.

"Fowler WM, Gardiner GW. Quantitative strength measurements in muscular dystrophy. Arch Phys Med Rehabil 1967;48:629-44.

${ }^{12}$ Hosking GP, Bhat US, Dubowitz V, Edwards RHT. Measurements of muscle strength and performance in children with normal and diseased muscle. Arch Dis Child 1976;51:957-63.

${ }^{13}$ de Lateur BJ, Giaconi RM. Effect on strength of submaximal exercise in Duchenne muscular dystrophy. Am J Phys Med 1979;58:26-36.

${ }^{14}$ Scott OM, Hyde SA, Goddard C, Dubowitz V. Quantitation of muscle function in children: a prospective study in Duchenne muscular dystrophy. Muscle Nerve 1982;5:291-301.

15 Dinsdale SM, Cole TM, Zaki IG, Awad EA. Measurements of disease activity in dermatomyositis. Arch Phys Med Rehabil 1972;52:201-6.

${ }^{16}$ Edwards RHT, Wiles CM, Round JM, Jackson MJ, Young A. Muscle breakdown and repair in polymyositis: a case study. Muscle Nerve 1979;2: 223-8.

${ }^{17}$ Resnick JS, Mammel M, Mundale MO, Kottke FJ. Muscular strength as an index of response to therapy in childhood dermatomyositis. Arch Phys Med Rehabil 1981;62:12-19.

${ }^{18}$ Wiles CM, Young A, Jones DA, Edwards RHT. Muscle relaxation rate, fibre type composition and energy turnover in hyper- and hypo-thyroid patients. Clin Sci 1979;57:375-84.

19 Young A, Edwards RHT, Jones DA, Brenton DP. Quadriceps muscle strength and fibre size during the treatment of osteomalacia. In: Stokes IAF, ed. Mechanical Factors and the Skeleton. London: John Libbey, 1981:137-45.

${ }^{20}$ Friman G. Effect of acute infectious disease on isometric muscle strength. Scand J Clin Lab Invest 1977; 37:303-8.

${ }^{21}$ Edwards RHT, Young A, Hosking GP, Jones DA. Human skeletal muscle function: description of tests and normal values. Clin Sci 1977;52:283-90.

22 Currier DP. Effect of back support and hip angles on knee extensor force. Physiotherapy Canada 1979; 31:334-6.

${ }^{23}$ Peacock B, Westers T, Walsh S, Nicholson K. Feedback and maximum voluntary contraction. Ergonomics $1981 ; 24: 223-8$. 
${ }^{24}$ Edwards RHT, McDonnell M. A hand-held clinical dynamometer for evaluating voluntary muscle function in patients. Lancet 1974;2:757-8.

${ }^{25}$ Edwards RHT, Hyde S. Methods of measuring muscle strength and fatigue. Physiotherapy 1977;63:51-5.

${ }^{26}$ Young $A$. The assessment of impaired muscle function by dynamometry. In: Feltkamp TEW, Van der Korst JK, eds. Disease Evaluation and Patient Assessment in Rheumatoid Arthritis. The Netherlands. Stafleu's Sci Publ. Alphen aan de Rijn, 1979:213-22.

${ }^{27}$ Wiles CM, Jones DA, Edwards RHT. Fatigue in human metabolic myopathy. In: Human Muscle Fatigue:
Physiological Mechanisms, Ciba Symposium No. 82. London: Pitman Medical, 1981:264-82.

28 Tornvall G. Assessment of physical capabilities with special reference to the evaluation of maximal voluntary isometric muscle strength and maximal working capacity Acta Physiol Scand 1963 Suppl. 201.

${ }^{29}$ Tourtellotte WW, Haerer AF, Simpson JF, Kuzma JW, Sikorski J. Quantitative clinical neurological testing. 1. A study of a battery of tests designed to evaluate in part the neurological function of patients with multiple sclerosis and its use in a therapeutic trial. Ann NY Acad Sci 1965;122:480-505. 